\title{
FAKTOR PREDIKTOR FINANCIAL MANAGEMENT BEHAVIOR GENERASI $\mathrm{X}$
}

\author{
Ida Ida $^{1^{*}}$, Sri Zaniarti ${ }^{2}$, Nabilla Ayuningtyas ${ }^{3}$ \\ ${ }^{1}$ Program Studi Manajemen, Universitas Kristen Maranatha Bandung \\ Email:ida@eco.maranatha.edu \\ ${ }^{2}$ Program Studi Manajemen, Universitas Kristen Maranatha Bandung \\ Email: sri.zaniarti@eco.maranatha.edu \\ ${ }^{3}$ Program Studi Manajemen, Universitas Kristen Maranatha Bandung \\ Email: nabillaayuningtyas2@gmail.com \\ *penulis korespondensi
}

Masuk : 12-04-2021, revisi: 16-04-2021, diterima untuk diterbitkan : 17-04-2021

\begin{abstract}
ABSTRAK
Kemudahan akses menggunakan internet dalam memenuhi kebutuhan manusia dapat meningkatkan konsumsi. Generasi X sebagai generasi yang mengenal komputer perlu memiliki financial management behavior yang baik agar tidak menimbulkan masalah keuangan. Studi ini bertujuan untuk menguji secara empiris faktor- faktor yang dapat digunakan sebagai prediktor financial management behavior generasi X. Data dikumpulkan dengan menyebarkan kuesioner secara elektronik kepada generasi X yang lahir tahun 1961- 1980 dan terdapat 579 responden yang mengisi lengkap serta diolah dengan menggunakan pendekatan PLS-SEM. Hasil pengolahan diperoleh bahwa self efficacy, internal locus of control, dan Financial Literacy dapat digunakan sebagai faktor yang dapat memprediksi financial management behavior generasi X di kota Bandung Raya dengan responden penelitian yang mayoritasnya berjenis kelamin laki- laki, pendidikan tertinggi Perguruan Tinggi dan bekerja sebagai pegawai. Hasil penelitian ini diharapkan dapat memberikan masukan bagi generasi $\mathrm{X}$ agar dapat terus meningkatkan self efficacy, internal locus of control, dan Financial Literacy sehingga dapat meningkatkan financial management behaviornya.
\end{abstract}

Kata Kunci: self efficacy, internal locus of control, Financial Literacy, financial management behavior, generasi X

\section{ABSTRACT}

Ease of access using the internet to meet human needs can increase consumption. Generation $X$ is the generation that knows computers. Generation X needs to have good financial management behavior so as not to cause financial problems. This study aimed to test empirically the factors that can be predictors of generation $X$ financial management behavior. The data were collected using questionnaires electronically to generation X (born in 1961 1980). There were 579 respondents. Data were processed using the PLS-SEM approach. The results of the processing show that self-efficacy, internal locus of control, and financial literacy can be used as factors that can predict the financial management behavior of generation $X$ in the city of Bandung Raya with the majority of research respondents who are male, the highest education is higher education and work as an employee. The results of this study are expected to provide input for generation $X$ to improve self-efficacy, internal locus of control, and financial literacy to improve their financial management behavior.

Keywords: self efficacy, internal locus of control, financial literacy, financial management behavior, generation X

\section{PENDAHULUAN}

\section{Latar Belakang}

Kemajuan teknologi internet telah merubah perilaku manusia saat ini. Kemudahan akses menggunakan internet dalam memenuhi kebutuhan manusia dapat meningkatkan konsumsi. Jika individu tersebut tidak memiliki financial management behavior yang baik, maka kemudahan akses internet bukan saja untuk pemenuhan kebutuhan tetapi akan menjadi pemenuhan keinginan. Hal ini dapat menimbulkan masalah keuangan jika pendapatan yang diperoleh tidak mencukupi. 
Berdasarkan Social Cognitive Theory Albert Bandura, Faktor yang memengaruhi behavior seseorang adalah personal factor dan environment factor (LaMorte, 2019). Personal factor seperti self efficacy dan locus of control. Environment factor seperti knowledge yang diperoleh dari institusi. Studi ini ingin menguji apakah personal factor yaitu self efficacy dan locus of control serta Environment factor yaitu financial literacy memengaruhi behavior seseorang dalam pengelolaan keuangannya. Perilaku yang tidak bijak dalam mengelola keuangan akan berdampak buruk bagi kondisi keuangan seseorang dan akan mendatangkan masalah- masalah keuangan sehingga menjadi penting agar dapat diketahui faktor- faktor yang dapat memprediksi financial management behavior suatu individu agar tidak terjerumus pada kesulitan keuangan.

Studi ini meneliti Generasi X yaitu generasi yang lahir pada tahun 1961- 1980 (Gursoy et al, 2008). Generasi $X$ sebagai generasi yang suka risiko dan memiliki pengambilan keputusan yang matang. Dari sisi teknologi, Generasi X mulai mengenal komputer sehingga generasi X mulai berpikir inovatif (Ramdhani, 2018). Selain itu, Generasi X juga dikenal mandiri dan bekerja dengan aturan yang jelas tetapi tidak kaku, (Nindyati, 2017).

Hasil penelitian terdahulu mengenai faktor- faktor sebagai prediktor financial management behavior telah dilakukan tetapi tidak dilakukan secara spesifik terhadap generasi $\mathrm{X}$ dan menunjukkan hasil yang bertolak belakang seperti hasil penelitian Rizkiawati \& Asandimitra (2018); Putri \& Pamungkas (2019); Ahmad, et al (2019) menunjukkan bahwa financial selfefficacy dapat memprediksi financial management behavior seseorang. Hal ini bertolak belakang dengan hasil kajian Alfanada et al (2021) menunjukkan financial self-efficacy bukan sebagai faktor yang dapat memprediksi financial management behavior seseorang.

Faktor lainnya adalah locus of control. Hasil studi Kholilah dan Iramani (2013) menunjukkan bahwa internal locus of control pada diri seseorang yang sangat baik, maka akan berpengaruh positif terhadap perilakunya dalam pengelolaan keuangan. Hal ini didukung oleh studi Arifin (2017); Putri dan Pamungkas (2019) yang menunjukkan bahwa terdapat pengaruh internal locus of control terhadap Financial Management Behavior. Tetapi hasil studi Amanah et al (2016); Prihartono \& Asandimitra (2018) menunjukkan bahwa internal locus of control tidak berpengaruh terhadap Financial Management Behavior.

Selanjutnya, hasil penelitian mengenai financial literacy sebagai faktor yang dapat memprediksi financial management behavior telah dilakukan oleh Mien \&Thao (2015); Henager \& Cude (2016), Ahmad, et al (2019); Ramadhan \& Asandimitra (2019), Aghababaei \& Khademi (2019); Asaff, et al (2019) dan Ida, et al (2020) menunjukkan hasil bahwa financial literacy sebagai faktor yang dapat memprediksi financial management behavior seseorang. Hal ini bertolak belakang dengan hasil penelitian Yap, et al (2016); Prihartono \& Asandimitra (2018); Purwidianti \& Tubastuvi (2019) yang menunjukkan financial literacy tidak dapat memprediksi financial management behavior seseorang.

\section{Financial Management Behavior}

Perilaku keuangan seseorang akan berhubungan dengan pengelolaan keuangan. Setiap orang mempunyai tanggung jawab atas pengelolaan keuangan mereka. Perilaku keuangan dengan baik akan menghasilkan pengelolaan keuangan dengan baik. Chien \& Endo (2012) mengemukakan bahwa seseorang yang mampu mengambil keputusan pengelolaan keuangan yang benar tidak akan terjebak pada kesulitan keuangan di masa yang akan datang dan akan memperlihatkan 
perilaku keuangan yang sehat dengan memperioritaskan pengeluaran sesuai kebutuhan bukan sesuai keinginan.

\section{Self Efficacy}

Setiap manusia mempunyai tujuan hidup keuangan yang berbeda-beda dan untuk mencapai tujuan hidup keuangan tersebut juga berbeda. Pencapaian tujuan hidup keuangan dibutuhkan pengelolaan keuangan dengan baik dan seseorang harus meyakinkan diri sendiri mampu untuk mengatur keuangan dengan baik. Oleh kerana itu, harus mampu merubah pola pikir dan perilaku terhadap uang dan meyakinkan diri mampu untuk melakukannya. Keyakinan diri tersebut disebut dengan self efficacy sebagai keyakinan sesorang bahwa ia mampu mengorganisir, menjalankan suatu tindakan agar mencapai tujuan yang diharapkan (Rizkiawati \& Asandimitra, 2018). Seseorang yang memiliki self efficacy tinggi akan mampu mengatasi hambatan- hambatan yang ada dan berusaha giat untuk mengubah hambatan- hambatan yang ada. Self Efficacy sangat penting dalam mengatur keuangan dengan baik karena dengan mempunyai keyakinan tinggi dalam pengelolaan keuangan maka akan memberikan hasil yang baik dan dapat menggunakan uang dengan bijak dan membeli barang sesuai dengan kebutuhan.

\section{Locus of Control}

Peran diri sendiri dan orang lain akan berpengaruh terhadap perilaku terhadap uang. Perilaku terhadap uang akan mempengaruhi dalam pengelolaan keuangan seseorang. Banyak orang akan beranggapan pengelolaan keuangan tergantung pada diri sendiri dan semua hal yang terjadi dalam hidup akibat dari sikap diri sendiri tetapi banyak juga yang beranggapan bahwa pengelolaan keuangan akan sangat berpengaruh dari kondisi luar dan semua kejadian yang terjadi dalam hidupnya tergantung dari kondisi luar diri. Menurut Pradiningtyas \& Lukiastuti (2019), locus of control merupakan tingkat seseorang percaya bahwa dia merupakan penentu nasibnya. Munir \& Sajid (2010) mengemukakan Locus of control sebagai gambaran individu yang cenderung percaya bahwa dia sebagai pengendali hidupnya. Locus of Control merupakan sesorang yang merasakan tindakan yang telah dilakukannya memiliki pengaruh pada kondisi kehidupan mereka dan sejauh mana akan menghubungkan keadaan dan ganjaran dengan takdir, keberuntungan dan kebetulan dan mempercayai keadaan dan ganjaran dipengaruhi oleh tindakan sendiri (Munir \& Sajid, 2010)

\section{Financial Literacy}

Pengetahuan keuangan adalah salah satu hal penting dalam perencanaan keuangan dan sikap seseorang terhadap uang. Setiap masyarakat menginginkan kehidupan yang lebih baik terutama dalam keuangan. Dalam mencapai keuangan yang baik maka diperlukan financial literacy yang baik dalam pengambilan keputusan keuangan. Kurangnya pengetahuan keuangan akan menyebabkan seseorang mengalami kesulitan keuangan. Pengetahuan keuangan harus mampu untuk dipahami dan dipelajari dengan baik oleh generasi $\mathrm{X}$ karena sifat dasar manusia adalah konsumtif sehingga jika pengelolaan keuangan tidak baik, maka akan mengalami kesulitan keuangan. Literasi keuangan merupakan kemampuan individu mengetahui bagaimana uang bekerja, bagaimana individu mendapatkan uang, bagaimana individu mengelola uang dan menginvestasikannya (Prihastuty \& Rahayuningsih, 2018). Literasi keuangan memberi keterampilan untuk menerapkan pengetahuan itu dalam kehidupan riil agar meraih kesuksesan di masa yang akan datang sehingga dapat meningkatkan taraf kehidupan karena melek dan sadar finansial yang tinggi. (Parrotta \& Johnson, 1998, dalam Yap, dkk, 2016)

\section{Pengaruh Self Efficacy terhadap Financial Management Behavior}

Self efficacy adalah keyakinan individu terhadap dirinya bahwa ia memiliki kemampuan untuk mengelola keuangan dan dapat mengambil keputusan keuangan yang efisien (Ahmad, et al, 
2019). Keyakinan seseorang bahwa dirinya mampu mengelola keuangan diharapkan dapat memengaruhi financial management behaviornya. Hal ini berarti semakin meningkat self efficacy maka semakin baik financial management behaviornya. Hasil penelitian Rizkiawati \& Asandimitra (2018); Ahmad, et al (2019); Putri \& Pamungkas (2019) menunjukkan self-efficacy sebagai faktor yang dapat memprediksi financial management behavior. Berdasarkan penjelasa ini, maka hipotesis satu penelitian ini adalah:

\section{$\mathrm{H}_{1}$ : Terdapat pengaruh positif Self Efficacy terhadap financial management behavior.}

\section{Pengaruh Internal locus of control terhadap Financial Management Behavior}

Julian Rotter, tahun 1966 mengemukakan mengenai locus of control. Individu yang mempunyai internal locus of control yang besar maka mereka mempunyai pemikiran bahwa pengendalian hidup mereka ada pada diri mereka sendiri (Achadiyah \& Laily 2013). Kholilah \& Iramani (2013) mengemukakan bahwa individu yang memiliki internal locus of control yang tinggi, maka akan berpengaruh positif terhadap perilakunya dalam pengelolaan keuangan. Hal ini didukung oeh hasil penelitian Kholilah \& Iramani (2013); Putri \& Pamungkas (2019) yang menemukan bahwa terdapat pengaruh internal locus of control terhadap Financial Management Behavior.Hasil penelitian Arifin (2017) juga menemukan bahwa internal locus of control memiliki pengaruh positif terhadap financial behavior. Dari penjelasan ini, maka hipotesis dua penelitian ini adalah:

\section{$\mathrm{H}_{2}$ : Terdapat pengaruh positif internal locus of control terhadap financial management behavior.}

\section{Pengaruh financial literacy terhadap Financial Management Behaviour}

Remund (2010) mengemukakan bahwafinancial literacy mempunyai kaitan dengan kompetensi individu dalam pegelolaan keuangan. Financial literacy dapat memengaruhi sikap seseorang dalam berperilaku khususnya perilaku dalam pengelolaan keuangannya (Herdjiono \& Damanik, 2016). Hal ini juga didukung oleh hasil kajian Ahmad, et al (2019) yang menghasilkan bahwa financial literacy sebagai prediktor terhadap financial behavior. Hasil penelitian Mien and Thao (2015); Henager \&Cude (2016); Ramadhan \& Asandimitra (2019); Aghababaei \& Khademi (2019); Asaff et.al (2019); Ida et al (2020) juga menunjukkan bahwa financial literacy sebagai faktor yang dapat meprediksi financial management behavior. Berdasarkan penjelasan ini, maka hipotesis tiga penelitian ini adalah:

\section{H3: Terdapat pengaruh positif financial literacy terhadap financial management behavior.}

\section{METODE PENELITIAN}

Penelitian ini merupakan penelitian descriptive. Menurut Sekaran \& Bougie (2013) penelitian decriptive merupakan penelitian yang dirancang untuk mengumpulkan data yang menggambarkan karakteristik orang, peristiwa, atau situasi. Penelitian ini bertujuan untuk menjelaskan karakteristik dari generasi X. Penelitian ini menggunakan cross-sectional designs dengan pengambilan informasi dari sampel tertentu dari elemen populasi hanya sekali (Sekaran \& Bougie, 2013). Data dikumpulkan dengan metode survei yaitu dengan menyebarkan kuesioner secara elektronik yang berisi pertanyaan mengenai self efficacy, financial literacy, locus of control, dan financial management behavior. Populasi dalam penelitian ini adalah generasi $\mathrm{X}$ (lahir tahun 1961-1980) yang tinggal di Bandung Raya dengan teknik pengambilan sampel menggunakan convenience sampling yaitu pengambilan sampel melibatkan elemen-elemen yang nyaman menurut peneliti (Sekaran \& Bougie, 2013). Jumlah sampel yang diteliti sebanyak 579 
responden dan mayoritas responden berjenis kelamin laki- laki sebanyak 301 (52\%), berpendidikan terakhir Perguruan Tinggi sebanyak 58.2\% (337 responden) dan memiliki pekerjaan sebagai pegawai sebanyak $35.9 \%$ (208 responden). Indikator pertanyaan yang digunakan dapat dilihat pada tabel 1 dengan menggunakan skala Likert dari Angka 1 sampai 4 yang menyatakan sangat tidak setuju sampai sangat setuju. Dari data yang terkumpul dianalisis dengan menggunakan pendekatan PLS-SEM.

Tabel 1. Indikator Variabel Penelitian

\begin{tabular}{|c|c|c|c|}
\hline Variabel & Indikator & Kode & Sumber \\
\hline \multirow{8}{*}{ Self efficacy } & Percaya pada diri sendri saat membuat keputusan tentang uang. & SE02 & \multirow{8}{*}{$\begin{array}{l}\text { Danes \& } \\
\text { Haberman (2007); } \\
\text { Laap (2010) }\end{array}$} \\
\hline & $\begin{array}{l}\text { Yakin mampu membuat perencanaan keuangan untuk masa } \\
\text { depan keuanganku. }\end{array}$ & SE03 & \\
\hline & Yakin dapat mengatasi tantangan kehidupan. & SE07 & \\
\hline & Orang yang tidak gampang putus asa. & SE08 & \\
\hline & $\begin{array}{l}\text { Kompeten untuk memecahkan persoalan keuangan yang saya } \\
\text { hadapi. }\end{array}$ & SE09 & \\
\hline & Yakin dapat berhasil mengelola uang. & SE11 & \\
\hline & Yakin dapat mengatasi tantangan dalam mengelola uang. & SE12 & \\
\hline & $\begin{array}{l}\text { Percaya akan berhasil mengelola uang dengan baik bahkan jika } \\
\text { tugas mengelola uang tersebut menjadi kompleks. }\end{array}$ & SE13 & \\
\hline \multirow{5}{*}{$\begin{array}{l}\text { Internal locus of } \\
\text { control }\end{array}$} & Memiliki inisiatif yang tinggi dalam melakukan pekerjaan. & ILC01 & \multirow{5}{*}{$\begin{array}{l}\text { Amalini, et al } \\
(2016)\end{array}$} \\
\hline & Memiliki motivasi yang besar dalam melakukan pekerjaan. & ILC 02 & \\
\hline & Puas atas prestasi yang diraih. & ILC03 & \\
\hline & Menyukai tantangan untuk maju & ILC 04 & \\
\hline & Prestasi mengarah pada reward yang berarti. & ILC05 & \\
\hline \multirow{3}{*}{ Financial literacy } & $\begin{array}{l}\text { Memiliki catatan tentang pengeluaran-pengeluaran apa saja } \\
\text { yang perlu, jika ingin berbelanja. }\end{array}$ & FL01 & \multirow{3}{*}{$\begin{array}{l}\text { Lusardi \& } \\
\text { Mitchell, (2007). }\end{array}$} \\
\hline & $\begin{array}{l}\text { Anggaran diri meliputi rencana untuk biaya darurat dan biaya- } \\
\text { biaya tidak diharapkan lainnya. }\end{array}$ & FL02 & \\
\hline & $\begin{array}{l}\text { Menggunakan pembukuan yang terencana untuk mengontrol } \\
\text { pengeluaran. }\end{array}$ & FL03 & \\
\hline \multirow{3}{*}{$\begin{array}{l}\text { Financial } \\
\text { management } \\
\text { behavior }\end{array}$} & Peduli terhadap jumlah uang yang dimiliki. & FMB01 & \multirow{3}{*}{$\begin{array}{l}\text { Grable \& Joo } \\
(2006) \text {. }\end{array}$} \\
\hline & $\begin{array}{l}\text { Tidak kesulitan membayar tagihan karena memiliki uang yang } \\
\text { cukup }\end{array}$ & FMB03 & \\
\hline & $\begin{array}{l}\text { Menjaga untuk tetap dalam rencana berapa banyak uang yang } \\
\text { akan dihabiskan setiap bulannya. }\end{array}$ & FMB07 & \\
\hline
\end{tabular}

\section{HASIL DAN PEMBAHASAN}

Hasil Uji Validitas

Hasil Uji Convergent Validity

Hasil uji convergent validity untuk Average Variance Extracted penelitian ini dapat dilihat pada tabel 2 dan hasil convergent validity untuk nilai outer loading dapat dilihat pada tabel 3 
Tabel 2. Hasil Average Variance Extracted

\begin{tabular}{cc}
\hline Variabel & $\begin{array}{c}\text { Average Variance Extracted } \\
\text { (AVE) }\end{array}$ \\
\hline Financial Literacy (FL) & 0.762 \\
\hline $\begin{array}{c}\text { Financial Management Behavior } \\
\text { (FMB) }\end{array}$ & 0.601 \\
\hline Internal Locus of Control (ILC) & 0.636 \\
\hline Self Efficacy (SE) & 0.675 \\
\hline
\end{tabular}

Tabel 3. Hasil Outer Loading

\begin{tabular}{|c|c|c|c|c|}
\hline & $\begin{array}{l}\text { Financial } \\
\text { literacy }\end{array}$ & $\begin{array}{l}\text { Financial } \\
\text { management } \\
\text { behavior }\end{array}$ & $\begin{array}{l}\text { Internal } \\
\text { locus of } \\
\text { control }\end{array}$ & $\begin{array}{l}\text { Self } \\
\text { efficacy }\end{array}$ \\
\hline FL1 & 0.864 & & & \\
\hline FL2 & 0.854 & & & \\
\hline FL3 & 0.900 & & & \\
\hline FMB1 & & 0.772 & & \\
\hline FMB3 & & 0.722 & & \\
\hline FMB7 & & 0.828 & & \\
\hline ILC1 & & & 0.851 & \\
\hline ILC2 & & & 0.808 & \\
\hline ILC3 & & & 0.743 & \\
\hline ILC4 & & & 0.794 & \\
\hline ILC5 & & & 0.789 & \\
\hline SE11 & & & & 0.840 \\
\hline SE12 & & & & 0.841 \\
\hline SE13 & & & & 0.835 \\
\hline SE2 & & & & 0.809 \\
\hline SE3 & & & & 0.813 \\
\hline SE7 & & & & 0.815 \\
\hline SE8 & & & & 0.766 \\
\hline SE9 & & & & 0.848 \\
\hline
\end{tabular}

Average Variance Extracted (AVE) tiap variabel pada tabel $2>0.5$ dan nilai loading factor pada tabel 3 telah melebihi 0.7 , maka variabel penelitian ini telah valid.

\section{Hasil Uji Discriminant Validity}

Pada tabel 4, Nilai korelasi variabel yang diamati lebih baik daripada menjelaskan variabel lainnya. Nilai korelasi tersebut merupakan akar kuadrat dari nilai AVE variabel yang diamati. Pada tabel 5, cross loading pada indikator dari konstruk yang diamati > cross loading pada indikator dari konstruk lainnya sehingga variabel penelitian ini sudah memiliki validitas diskriminan yang baik. 
Tabel 4. Hasil Discriminant Validity (Fornell-Larker Creation)

\begin{tabular}{ccccc}
\hline & $\begin{array}{c}\text { Financial } \\
\text { Literacy (FL) }\end{array}$ & $\begin{array}{c}\text { Financial } \\
\text { Management Behavior } \\
\text { (FMB) }\end{array}$ & $\begin{array}{c}\text { Internal Locus } \\
\text { of Control } \\
\text { (ILC) }\end{array}$ & $\begin{array}{c}\text { Self } \\
\text { Efficacy } \\
\text { (SE) }\end{array}$ \\
\hline Financial Literacy (FL) & 0.873 & & & \\
\hline Financial Management Behavior (FMB) & 0.645 & 0.775 & & \\
\hline Internal Locus of Control (ILC) & 0.573 & 0.607 & 0.797 & 0.821 \\
\hline Self Efficacy (SE) & 0.659 & 0.642 & 0.670 & 0.06 \\
\hline
\end{tabular}

Tabel 5. Hasil Discriminant Validity (Cross Loading)

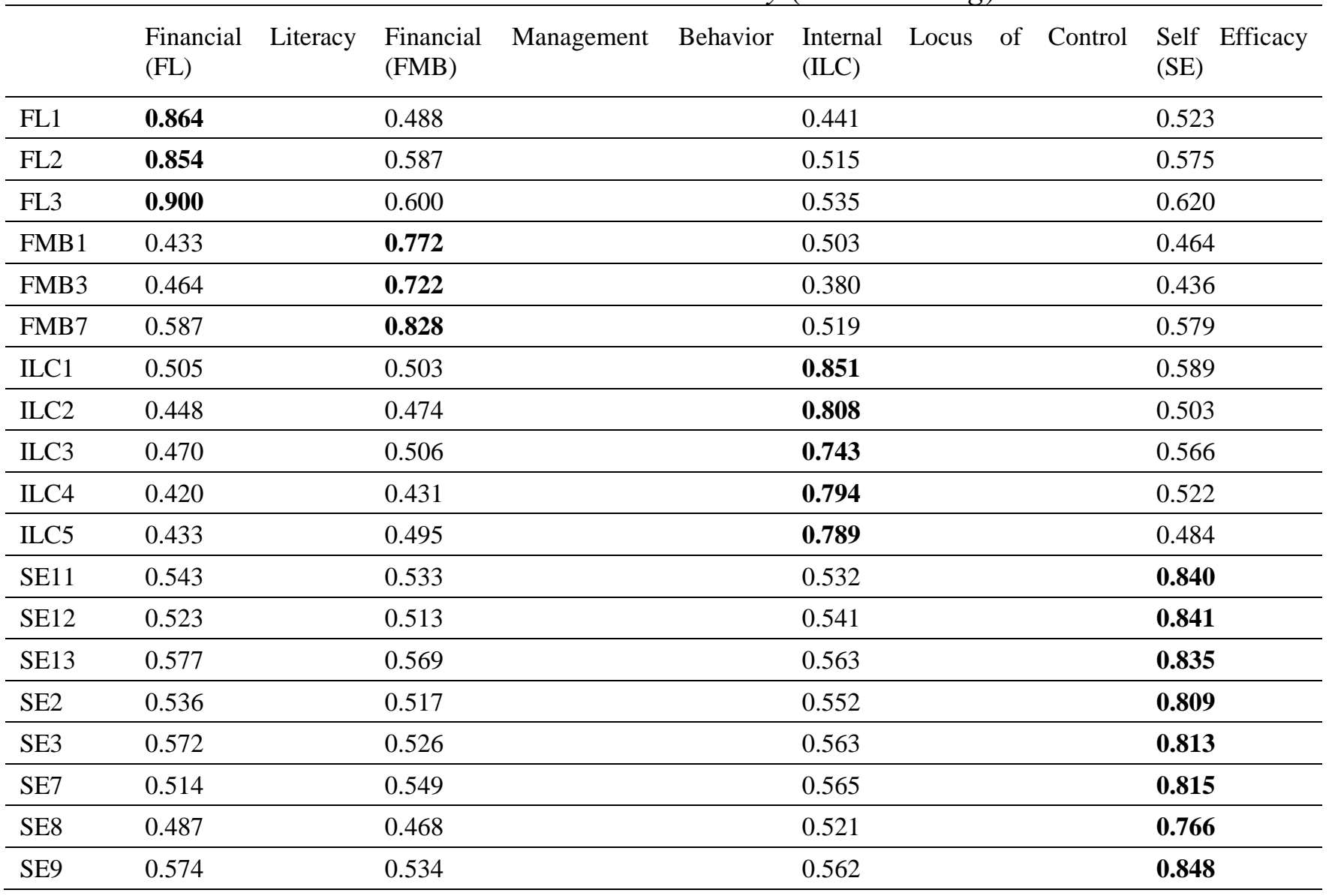

\section{Hasil Uji Reliabilitas}

Studi ini menggunakan cronbach's alpha dan composite reliability sebagai pengukur reliabilitas terhadap variabel yang diamati. Tabel 6 menunjukkan hasil dari uji reliabilitas.

Tabel 6. Hasil Uji Reliabilitas

\begin{tabular}{ccc}
\hline & Cronbach's Alpha & Composite Reliability \\
\hline Financial Literacy (FL) & 0.844 & 0.906 \\
\hline Financial Management Behavior (FMB) & 0.669 & 0.818 \\
\hline Internal Locus of Control (ILC) & 0.856 & 0.897 \\
\hline Self Efficacy (SE) & 0.931 & 0.943 \\
\hline
\end{tabular}


Berdasarkan Tabel 6 diperoleh hasil bahwa nilai cronbach's alpha masing- masing variabel > 0.6 dan composite reliability $>0.7$ maka dapat dinyatakan bahwa variabel penelitian ini reliabel. Hasil pengolahan PLS algorithm dapat dilihat pada gambar 1

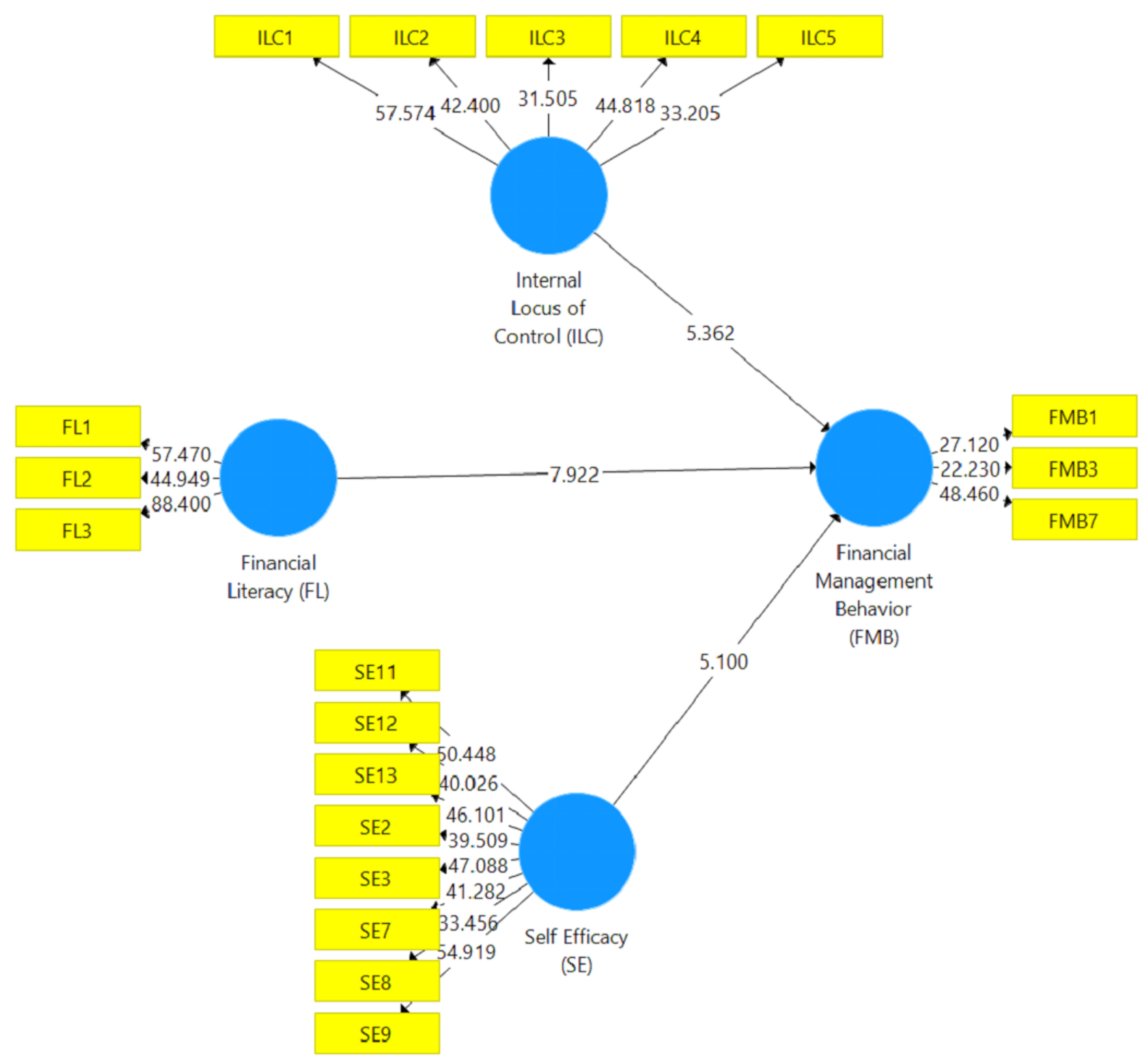

Gambar 1 Hasil pengolahan PLS algorithm

\section{Hasil Coefficient Of Determination $\left(\mathbf{R}^{2}\right)$}

Berdasarkan hasil analisis R-square terhadap model penelitian yang didapatkan dari analisis data pada tabel 7 diperoleh bahwa nilai R-square adalah 0.529 (52.9\%). Dapat diartikan bahwa variabel self efficacy, locus of control, dan financial literacy dalam penelitian ini memberikan pengaruh sebesar 52.9\% terhadap financial management behavior; sedangkan sisanya $(47.1 \%)$ dipengaruhi oleh variabel lainnya di luar dari variabel yang diteliti seperti financial attitude, money attitude- power prestige, income. 
Tabel 7. Hasil Coefficient Of Determination $\left(\mathrm{R}^{2}\right)$

\begin{tabular}{lc}
\hline Variabel & R Square \\
\hline Financial Management Behavior (FMB) & 0.529 \\
\hline
\end{tabular}

Tabel 8. Hasil Uji Hipotesis

\begin{tabular}{llllll}
\hline Hipotesis & Keterangan & T Statistics & P Values \\
\hline Pertama & Self Efficacy (SE) -> Financial Management Behavior (FMB) & 5.255 & 0.000 \\
\hline Kedua & $\begin{array}{l}\text { Internal Locus of Control (ILC) } \\
\text { Behavior (FMB) }\end{array}$ & Financial Management & 5.356 & 0.000 \\
\hline Ketiga & $\begin{array}{l}\text { Financial Literacy (FL) } \\
\text { (FMB) }\end{array}$ & Financial Management Behavior & 7.486 & 0.000 \\
\hline
\end{tabular}

\section{Pembahasan}

Hipotesis satu pada studi ini menyatakan bahwa terdapat pengaruh positif self efficacy terhadap financial management behavior. Hasil uji hipotesis pada tabel 8 menunjukkan nilai $\mathrm{P}$ values sebesar $0.000<0.05$ dan T statistics positif, hal ini mendukung hipotesis satu dan sejalan dengan hasil penelitian Rizkiawati \& Asandimitra (2018); Putri \& Pamungkas (2019); Ahmad, et al (2019). Hal ini berarti self efficacy memiliki hubungan yang positif terhadap financial management behavior generasi $\mathrm{X}$. Individu yang memiliki self efficacy yang tinggi akan memungkinkan individu tersebut memiliki financial management behavior yang baik. Individu yang memiliki self efficacy yang tinggi yang dapat ditandai dengan keyakinannya dalam pengelolaan keuangan serta dapat membuat keputusan yang berkaitan dengan keuangan secara efisien dapat memengaruhi financial management behaviornya. Generasi X sebagai generasi yang dikenal mandiri perlu meningkatkan self efficacy yang dapat berpengaruh pada peningkatan financial management behaviornya.

Hipotesis dua pada penelitian ini menyatakan bahwa ada pengaruh positif internal locus of control terhadap financial management behavior. Hasil uji hipotesis pada tabel 8 menunjukkan nilai $\mathrm{P}$ values sebesar $0.000<0.05$ dan T statistics positif, hal ini mendukung hipotesis dua dan sesuai dengan hasil penelitian Kholilah \& Iramani (2013); Arifin (2017); Putri \& Pamungkas (2019) Hal ini berarti individu yang mempunyai internal locus of control yang tinggi akan memiliki hubungan yang positif pada financial management behaviornya. Individu yang memiliki pemikiran bahwa merekalah pengendali kehidupan mereka sendiri akan berpengaruh positif terhadap perilakunya dalam pengelolaan keuangan. Hal ini sesuai dengan karakteristik Generasi X sebagai generasi yang dikenal memiliki pengambilan keputusan yang matang yang memiliki keyakinan bahwa mereka memegang kendali pada hal yang terjadi pada dirinya, sehingga mereka perlu meningkatkan internal locus of controlnya agar dapat berpengaruh terhadap financial management behaviornya dan terbebas dari kesulitan keuangan.

Hipotesis tiga pada penelitian ini adalah ada pengaruh positif financial literacy terhadap financial management behavior. Hasil uji hipotesis pada tabel 8 menunjukkan nilai $\mathrm{P}$ values sebesar $0.000<0.05$ dan $\mathrm{T}$ statistics positif, hal ini mendukung hipotesis kedua dan sejalan dengan hasil penelitian Mien and Thao (2015); Henager \& Cude (2016); Ramadhan dan Asandimitra (2019); Aghababaei and Khademi (2019); Ida et al (2020). Hal ini berarti financial literacy memiliki hubungan positif dengan kompetensi seseorang dalam mengelola keuangan. Financial literacy dapat memengaruhi sikap seseorang dalam berperilaku khususnya perilaku dalam pengelolaan keuangannya. Hal ini berarti generasi $\mathrm{X}$ perlu meningkatkan financial literacynya yang akan memengaruhi financial management behaviornya. 


\section{KESIMPULAN DAN SARAN}

Hasil studi pada penelitian ini diperoleh bahwa self efficacy, internal locus of control, dan Financial Literacy dapat digunakan sebagai faktor yang dapat memprediksi financial management behaviour generasi $\mathrm{X}$ di kota Bandung Raya dengan responden penelitian yang mayoritasnya berjenis kelamin laki- laki, pendidikan tertinggi Perguruan Tinggi dan bekerja sebagai pegawai.

Saran yang dapat diberikan dari hasil studi ini adalah perlunya self efficacy, internal locus of control, dan Financial Literacy untuk dapat memeroleh financial management behavior yang lebih baik bagi generasi X. Hasil penelitian ini diharapkan dapat memberikan masukan bagi generasi $\mathrm{X}$ agar dapat terus meningkatkan kepercayaan pada dirinya sendiri bahwa mereka mampu mengelola dan membuat keputusan keuangan, tidak mudah putus asa, meningkatkan inisiatif dalam melakukan pekerjaan, menyukai tantangan, puas akan prestasi yang telah dicapai, memiliki tantangan untuk terus maju, selalu membuat catatan pengeluaran, dan mengontrol pengeluaran sehingga dapat meningkatkan financial management behaviornya.

Keterbatasan dalam penelitian adalah variabel yang digunakan hanya variabel self efficacy, internal locus internal, dan financial literacy dalam meneliti variabel yang memengaruhi financial management behaviour. Masih terdapat variabel lain yang belum diteliti yang berhubungan dengan financial management behavior.

\section{Ucapan Terima Kasih (Acknowledgement)}

Penulis menyampaikan terima kasih pada Universitas Kristen Maranatha yang telah memberikan bantuan pendanaan pada penelitian ini dan responden yang telah bersedia membantu pengisian kuesioner penelitian ini sehingga penelitian ini dapat selesai.

\section{REFERENSI}

Achadiyah, B. N. \& Laily, N. (2013). Pengaruh locus of control terhadap hasil belajar mahasiswa akuntansi. Jurnal Pendidikan Akuntansi Indonesia, 11(2), 11-18.

Aghababaei, M.E. \&Khademi, S. (2019). Factors affecting personal financial management behaviors - The case of Iranian youth. Journal of Financial Management Strategy, 7(24), 123-143.

Ahmad, A., Butt, B. S., Moazzam, \& Iram, S. (2019). Drivers influencing financial behavior among management students in Narowal. International Journal of Academic Research in Business and Social Sciences, 9(2), 656-666.

Alfanada, N., Azib, A., Setiyawan, S. (2021) Pengaruh financial knowledge, financial attitude, dan financial self efficacy terhadap financial management behavior (Studi kasus pada generasi milenial di Kota Bandung). Seminar Penelitian Sivitas Akademika Unisba, 7(1). http://dx.doi.org/10.29313/.v7i1.27103

Amalini, H.F., Musadieq, M.A., \&Afrianty, T.W. (2016). Pengaruh locus of control terhadap kepuasan kerja dan kinerja (Studi pada karyawan Perusahaan Daerah Air Minum (PDAM) Kota Malang). Jurnal Administrasi Bisnis, 35(1), 68- 77, diperoleh dari http://administrasibisnis.studentjournal.ub.ac.id/index.php/jab/article/view/1344

Amanah, E., Rahadian,D., Iradianty, A. (2016) Pengaruh financial knowledge, financial attitude dan external locus of control terhadap personal financial management behavior pada mahasiswa s1 universitas telkom. e-Proceeding of Management 3(2).

Arifin, A. Z. (2017). The influence of financial knowledge, control and income on individual finanical behavior. European Research Studies Journal, Xx(3a),635-648. 
Asaff, R., Suryati, \&Rahmayani, R. (2019). Pengaruh financial attitude dan financial knowledge terhadap financial management behavior(Studi kasus pada mahasiswa Fakultas Ekonomi konsentrasi keuangan Universitas Andi Djemma Palopo). Jurnal of economic, management and accounting (JEMMA), 2(2), 9-22.

Chien, K., \& Endo, H. (2012). Effects of attitude and background on students' personal finance ability : A United State Survey. International Journal of Management, 29 (2), 778- 791.

Danes, S. M., \& Haberman, H. R. (2007). Teen financial knowledge, self-efficacy, and behavior: A gendered view. Journal of Financial Counseling and Planning, 18(2), 48-60.

Grable, J.E. \& Joo, S.H.(2006). Student racial difference in credit card debt and financial behaviors and stress. College Student Journal, 40(2), 400-408.

Gursoy, D., Maier, T.A. \& Chi, C.G. (2008). Generational differences: An examination of work values and generational gaps in the hospitally workforce. International Journal of Hospitally Management, 27,448-458

Henager, R. \&Cude, B.J. (2016). Financial literacy and long- and short-term financial behavior in different age groups. Journal of Financial Counseling and Planning, 27(1), 3-19. Diperoleh darihttp://dx.doi.org/10.1891/1052-3073.27.1.3

Herdjiono, I., \& Damanik, L.A. (2016). Pengaruh financial attitude, financial knowledge, parental income terhadap financial management behavior. Jurnal Manajemen Teori dan Terapan, 9(3), 226-241.

Ida, I., Zaniarti, S., Wijaya, G. (2020) Financial literacy, money attitude, dan financial management behavior generasi milenial. Jurnal Muara Ilmu Ekonomi dan Bisnis, 4(2). http://dx.doi.org/10.24912/jmieb.v4i2.9144

Kholilah, N. Al., \& Iramani, R. (2013). Studi financial management behavior pada masyarakat surabaya. Journal of Business and Banking, 3(1), $69-80$.

LaMorte, W.W. (2019) The social cognitive theory. Behavioral Change Model. Diperoleh dari http://sphweb.bumc.bu.edu/otlt/MPHModules/SB/BehavioralChangeTheories/BehavioralChangeTheories5.html

Lapp, W. M. (2010). The Missing Link: Financial Self-Efficacy's Critical Role in Financial Capability. EARN White Paper

Lusardi, A.\& Mitchell, O.S. (2007). Baby boomer retirement security: The roles of planning, financial literacy, and housing wealth. Journal of Monetary Economics, 54(1), 205224.Diperoleh dari https://doi.org/10.1016/j.jmoneco.2006.12.001

Mien, N.T.G.\& Thao, T.P. (2015). Factors affecting personal financial management behaviors: Evidence from Vietnam. Proceedings of the Second Asia-Pacific Conference on Global Business, Economics, Finance 1- 16). Danang, Vietnam. Diperoleh dari http://globalbizresearch.org/Vietnam_Conference/pdf/VL532.pdf

Munir, S., \& Sajid, M. (2010). Examining locus of control (LOC) as a determinant of organizational commitment among university professors in Pakistan. Journal of Business Studies Quarterly, 1 (3), 78-93.

Nindyati AD. (2017). Pemaknaan loyalitas karyawan pada generasi x dan generasi y (studi pada karyawan di Indonesia). Journal of Psychological Science and Profesion (JPSP) 1(1):5966.

Pradiningtyas, T.E., \& Lukiastuti, F. (2019). Pengaruh pengetahuan keuangan dan sikap keuangan terhadap locus of control dan perilaku pengelolaan keuangan mahasiswa ekonomi. Jurnal Minds: Manajemen Ide dan Inspirasi, 6 (1), 96-112.

Prihartono, M.R.D., \& Asandimitra, N. (2018). Analysis factors influencing financial management behavior. International Journal of academic Research in Business \& Social Sciences, 8 (8), 308-326. 
Prihastuty, D.R., \& Rahayuningsih, S. (2018). Pengaruh financial literacy, financial behavior, financial attitude, dan demografi terhadap perilaku konsumtif (studi pada mahasiswa strata I fakultas ekonomi universitas 17 Agustus 1945 Surabaya). Jurnal Hasil Penelitian LPPM Untag Surabaya, 3 (2), 121-134.

Purwidianti, W., \& Tubastuvi, N. (2019). The effect of financial literacy and financial experience on sme sinancial behavior in Indonesia. Jurnal Dinamika Manajemen, 10 (1), 40-45.

Putri, M.H. dan Pamungkas, A.S. (2019) Pengaruh financial knowledge, locus of control dan financial self efficacy terhadap financial behavior. Jurnal Manajerial dan Kewirausahaan, 1(4), 890-889.

Ramadhan, A.Y. and Asandimitra, N (2019). Determinants of financial management behavior of millennial generation in surabaya.Jurnal Minds: Manajemen Ide dan Inspirasi, 6(2), 129144.

Ramdhani, G. ( 2018). Kenali karakter dan pola pikir 5 generasi ini agar semakin bijak. Diperoleh dari https://www.liputan6.com/lifestyle/read/3677417/kenali-karakter-danpola-pikir-5-generasi-ini-agar-semakin-bijak

Remund, D. L. (2010). Financial literacy explicated: The case for a clearer definition in an increasingly complex economy. Journal of Consumer Affairs, 44(2), 276-295. Diperoleh darihttp://dx.doi.org/10.1111/j.1745-6606.2010.01169.x

Rizkiawati, N.L., \& Asandimitra, N. (2018). Pengaruh demografi, financial knowledge, financial attitude, locus of control, dan financial self efficacy terhadap financial management behavior masyarakat Surabaya. Jurnal Ilmu Manajemen, 6 (3), 93-107. Diperoleh dari http://jurnalmahasiswa.unesa.ac.id/index.php/jim/article/view/23846/21793

Sekaran, U. \& Bougie, R. (2013). Research Methods for Business: A Skill-Building Approach. Sixth Edition. John Wiley \& Sons Ltd, United Kingdom.

Yap, R.J.C., Komalasari Farida., \& Hadiansah, I. (2016). The effect of financial literacy and attitude on financial management behavior and satisfaction. International Journal of Administrative Science \& Organization, Vol. 23 (3), 140-146 